\title{
Self-Determination
}

\section{The Tyranny of Freedom}

\author{
Barry Schwartz \\ Swarthmore College
}

Americans now live in a time and a place in which freedom and autonomy are valued above all else and in which expanded opportunities for self-determination are regarded as a sign of the psychological well-being of individuals and the moral well-being of the culture. This article argues that freedom, autonomy, and self-determination can become excessive, and that when that happens, freedom can be experienced as a kind of tyranny. The article further argues that unduly influenced by the ideology of economics and rational-choice theory, modern American society has created an excess of freedom, with resulting increases in people's dissatisfaction with their lives and in clinical depression. One significant task for a future psychology of optimal functioning is to deemphasize individual freedom and to determine which cultural constraints are necessary for people to live meaningful and satisfying lives.

Security is more important than wealth.

-Jacob von Uexkull (1938/1954, p. 26)

et me tell you about an experience I had almost 20 years ago. It happened at a softball game, and to understand it, you need to know a little bit about softball. Imagine a situation in which there is a runner at first base and one out. A ground ball is hit to the pitcher. The pitcher fields the ground ball and wheels around to second base. The idea is to try for a double play by throwing to second ahead of the runner arriving from first, and then having the throw relayed from second to first, in time to beat the batter. Typically, when a ball is hit up the middle of the diamond, the second baseman and the shortstop converge at second base. When the pitcher fields the ball and turns to throw, the proper play is to throw the ball to the shortstop. The shortstop is moving toward first base, while the second baseman is moving away from it. So the shortstop's momentum will carry him in the direction that the ball must be thrown, whereas the second baseman will have to stop, pivot, and then throw. The throw from second to first is much easier for the shortstop than for the second baseman.

Now here is what happened. I had just begun a sabbatical, and I was playing in a relaxed coed softball game. Although winning at all costs was not the idea in this game, there was one thing about it that was notably more serious than anything else. The women in the game did not want to be patronized; they wanted to be treated by the men as full-fledged competitors. So I was pitching, and there was one out and a runner on first. A ground ball was hit to me. I fielded it cleanly and spun around to begin the try for a double play. Both the shortstop, a man, and the second baseman, a woman, were converging on second base to receive my throw. I wound up to throw and then stopped in my tracks. Who should I throw to? I knew, as I just indicated, that the "right" play was to throw to the shortstop, but I hesitated. Would the woman understand that I was throwing to the shortstop (who happened to be a man) because it was the right play? Or would she think that I was excluding her and throwing to the man (who happened to be the shortstop) because I thought he was more likely to catch it and throw accurately on to first than she was? Would she think that I regarded her as an obstacle to be avoided rather than as a teammate? Would she think I was an enemy of one of the major social movements of our time?

These questions flooded over me in what couldn't have been more than half a second, and I still haven't answered them. Why had I been so indecisive? What was the right play? Yes, I knew that the right play was to throw to the shortstop, but I came to realize that the rightness of that choice depended on what I thought the game was that we were playing. If we were merely playing softball, then the shortstop should have gotten the throw, but we were playing more than softball. We were also participating in a social movement, one that was struggling to eliminate certain well-established gender roles, and we were involved in a complex social interaction, in which the feelings and objectives of all participants were to be taken seriously. What's the right play in that kind of a game?

When I finally threw the ball, I found an ingenious though unintended way out of my indecision. My agonized delay had forced me to rush my throw, so I "solved" my problem in deciding whether the second baseman or the shortstop should get the ball by throwing it to neither of them. I threw it three feet over both of their heads into centerfield. No double play. No single play. And that's no

Barry Schwartz, Department of Psychology, Swarthmore College.

Preparation of this article was supported by a faculty research grant from Swarthmore College. I thank Jane Gillham and Andrew Ward for many helpful discussions of the issues raised in this article.

Correspondence concerning this article should be addressed to Barry Schwartz, Swarthmore College, 500 College Avenue, Swarthmore, PA 19081. Electronic mail may be sent to bschwarl@swarthmore.edu. 


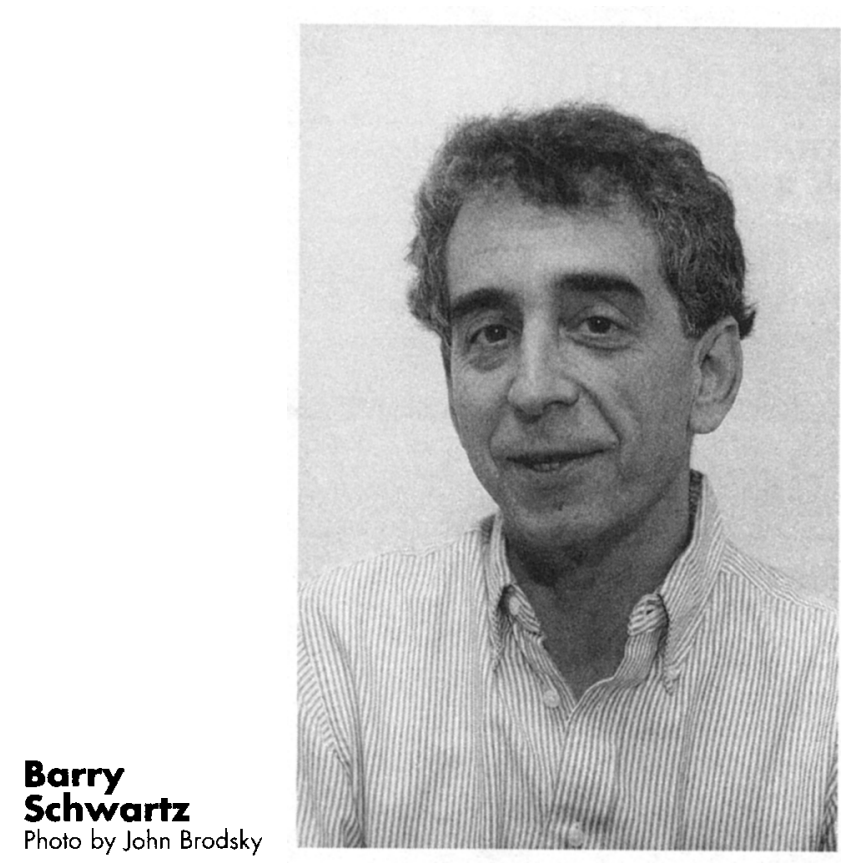

way to play at all. I was confused about what to do, and I screwed up.

This experience of mine on the softball field was trivial, but I think it is an example of problems faced by many of us that are not so trivial. Repeatedly, people are forced to ask themselves what kind of game they are playing, and what the right play is in that kind of game. A lot more rides on the answers to the versions of these questions people face in real life than just the completion of a double play.

What kind of game is being a student? Are the objectives of the student game to get the best grades possible? If so, a good student will find the easy courses, borrow (or buy or steal) other students' assignments, and ingratiate himself or herself in every way possible with the relevant teachers. Are the objectives of the student game to prepare for a career that will be financially rewarding? Are they to prepare for a career that will be intellectually rewarding? Are they to prepare for a career that will serve the public? In any of these cases, a good student will map out a program that provides appropriate training and then work hard to develop the skills necessary for success in that career. Possibly, the objectives of the student game have nothing to do with careers but instead involve becoming a knowledgeable, sensitive, compassionate, committed, ethical person who will be an informed and responsible citizen. The good student at this game will look very different from the good student at the other games.

What kind of game is being a businessperson? Are there any limits to what a businessperson should do in the service of corporate interests? If so, who sets the limits, and what are they? Should businesspeople be concerned about ethics and fairness? Should they seek to provide a good or service that the world genuinely needs? Should they be honest with their customers and clients? Or should they make whatever people will buy, tell people whatever they think people will believe, and break any law if they think they can get away with it?

What kind of game is being a spouse or a lover? To what extent are lovers supposed to submerge their own interests or desires to serve the interests or desires of their partners? At what point does devotion turn into subjugation? At what point does self-actualization turn into selfishness?

Most of us play in several of these games simultaneously and find ourselves trying to answer questions like these about each of them, because the world in which we "modern, enlightened, rational" people live is one in which the objectives and the rules of each of our games are very much up for grabs. Modernity has taught us not to accept a certain way of doing things just because things have always been done in that way. Nowadays, it is possible, maybe even necessary, for individuals to make up the rules of games as they go along.

This modern flexibility in the construal and construction of the objectives and the rules of the "games" we play enhances our sense of self-determination, and it is selfdetermination that this article is about. The presumption in modern society is that self-determination is a good thing, both psychologically and morally. Freedom and autonomy are words that come to mind as rough synonyms. Before pursuing this presumption, it is worth thinking a little about what self-determination means. Does it mean determination by the self, or determination of the self, or both? Determination by the self, which I suspect is what most people mean by self-determination, leads to the further question, determination of what? The answer to this question is pretty much determination of everything. From trivial things like choices of ice cream flavors, television shows, clothing styles, and objectives in softball games to crucial things like choices of careers, places to live, friends, and lovers, there is simply no such thing as too much freedom. What about determination of the self? What does this mean? I think it means that people are free to determine what kind of self they will have, what kind of people they will be. People are free to be selfish or selfless, nasty or nice, serious or frivolous, and they are free to change the selves they have as they see fit. Selves are like shirts. One can discard old ones and invent new ones. At least one should be able to, in keeping with the goal of maximal self-determination as a desirable psychological and moral state. Thus, the fully self-determined self is one that is completely unconstrained - by habit, by social convention, or by biology. Operating without constraint, the self-determining self makes choices in the world to maximize his or her preferences, in keeping with the principles of rational choice (von Neumann \& Morgenstern, 1944).

It is the central argument of this article that this aspiration to self-determination, presumably through processes resembling those of rational choice, is a mistake, both as an empirical description of how people act and as a normative ideal. It is a mistake because when selfdetermination is carried to extremes, it leads not to freedom 
of choice but to tyranny of choice. A better (empirically more accurate and psychologically healthier) model of self-determination is, I think, akin to our understanding of human linguistic abilities. The capacity to use language is perhaps the single most liberating characteristic of human beings. It frees people in significant ways from the temporal and material limitations that afflict other organisms. People can say anything about anything, at any time, or in any place-even things, times, and places that have never existed-and they can be understood. Therefore, language is probably as vivid an embodiment of human freedom and self-determination as anything. But what decades of research on language ability have made clear is that the thing that makes the liberating features of language possible is that language is heavily constrained by rules. The reason people can say anything and be understood is that they can't say everything. It is linguistic constraint, in the form of these rules, that makes linguistic freedom possible. What I suggest in this article is that exactly the same thing may be true in connection with self-determination. Unconstrained freedom leads to paralysis and becomes a kind of self-defeating tyranny. It is self-determination within significant constraints - within rules of some sort - that leads to well-being, to optimal functioning. The task for a future psychology of optimal functioning is to identify which constraints on self-determination are the crucial ones.

To make this argument, I begin by considering a few aspects of rational-choice theory in some detail. There are problems with rational-choice theory as an empirical description of how people choose, and many of these problems are a reflection of important constraints on freedom of choice that the theory of rational choice leaves out and that a positive theory of self-determination must include. What we see is that these constraints function not to impede truly rational choice but to enable it.

\section{Preference, Choice, and Decision Frames}

Based largely on economics, rational-choice theory has tried to explain human preference and choice by assuming that people are rational choosers. According to the choice theorist, human beings have well-ordered preferencespreferences that are essentially impervious to variations in the ways the alternatives they face are described or the ways they are packaged or bundled. People go through life with all their options arrayed before them, as if on a buffet table. They have complete information about the costs and benefits associated with each option. They compare the options to one another on a single scale of preference, or value, or utility. After making the comparisons, people chose so as to maximize their preferences, or values, or utilities. Well-being is understood to involve maximizing the possibilities for choice, maximizing the number of available options. A self is just the bundle of preferences that happen to coexist inside a single skin, and self-determination is just the unfettered pursuit of those preferences.

Rational-choice theory is largely silent about where preferences come from; preferences are frequently described as exogenous to the model of rational choice, meaning both that the model has nothing to say about them and that whatever the story on the origins of preferences may turn out to be, the power and validity of the model will be unaffected by it. Although the former claim may well be true, the latter is not (see Bowles, 1998). Human beings violate the principles of rational choice routinely (e.g., Kahneman \& Tversky, 1979, 1984; Tversky \& Kahneman, 1981; see Baron, 1994; Schwartz, 1986, 1994, for discussion), and the cause and character of many of these violations cannot be understood without understanding the nature and origins of preferences themselves (see McCauley, Rozin, \& Schwartz, 1999). Making sense of people's choices requires knowledge of the cultural institutions that influence their lives. Indeed, how closely people approximate the rational-choice theorist's portrait of preference and choice depends on the kind of culture they inhabit.

Rational-choice theorists tell us that rational choosers should always be able to express preferences. What this means is not that one thing will always be preferred to another, but that questions about preference will always be intelligible. People will, for any $A$ and $B$, be able to compare the choices and say that they prefer $A$ to $B$, that they prefer $B$ to $A$, or that they are indifferent between them. Is this claim accurate? Imagine someone who has just been given a gift of $\$ 100$. Should the person have a fine meal, buy a few shirts, take a friend to the theater, or buy several books? After some reflection, the person may well be able to rank these options, which is to say that he or she can express preferences among them.

However, these options do not exhaust the things that can be done with $\$ 100$. It can be given to any of a number of charities, or it can be used to buy groceries, to have the house cleaned, to buy school books, for part of the plane fare to a vacation spot, for part of the cost of having the house painted, to have someone care for the lawn, or to look after the children. The list of things one could do with $\$ 100$ is endless. Can people express preferences among all these different possibilities? Is a good meal preferred to having the house painted? Is child care preferred to a vacation? Everyone may be able intelligibly to express preferences among some of the things that can be done with $\$ 100$, but no one can express preferences among all of the things that can be done with $\$ 100$.

Indeed, nowadays the range of choices we face-even among similar kinds of things-is overwhelming. We go to the grocery and stop in the cereal aisle. Should we buy hot or cold? Should we buy sugarcoated or (relatively) unsweetened? Should we buy with or without bran? Should we buy all bran, oat bran, rice bran, corn bran, cracklin' bran, raisin bran, honey bran, or nut bran? We go to buy a car. Should we buy new or used? Foreign or domestic? Automatic or stick? Station wagon or sedan? Two-door or four-door? Six-cylinder or four-cylinder? The array of options we face is simply mind-numbing. Thus, even when we are faced with a choice among similar kinds of things, the task is daunting. When the possibilities include things with little or nothing in common, the problem is overwhelming. 
A person would, of course, eventually do something with the $\$ 100$ (and from the perspective of an idea in economics known as the theory of revealed preferencethe economist's version of behaviorism-what people finally do with that $\$ 100$ is, by definition, what they prefer over all other possibilities). How would he or she decide to do something with it instead of sitting paralyzed with uncertainty while the $\$ 100$ accumulates interest in a bank account? One way of thinking about just how people go about making choices is the idea that they organize the world of possibilities into a set of distinct categories, categories like household necessities, household maintenance, charity, one-night indulgences, longer term indulgences, personal appearance. Within each category, it may be relatively easy to express preferences. Between categories, however, expressing preferences is more problematic. According to this view, when faced with the problem of spending $\$ 100$, one must first decide what category of thing to spend it on. Once that is decided, one can follow the dictates of preference within a category.

This formulation raises several questions. How does one decide which categories to divide the world into? How does one decide which specific things go in which categories? And how does one decide which category to devote this $\$ 100$ to? The choice theorist's story about preference and choice has nothing to say about the first two questions. There are many factors that might influence the way in which people categorize possibilities. Habit is one source of influence, though it is important to note that people will often be inarticulate, if not completely unaware, when asked about their reasons for doing things that they do out of habit (somewhat like a fish in water, never noticing that it is wet). Cultural norms are another source of influence. In our culture, clothing and hair care may both be considered as pertaining to matters of appearance. However, one could easily imagine a culture in which what people wear has deep social-even religious-significance, whereas how they keep their hair is a trivial detail. In that culture, a haircut and a new shirt would not be lumped together. What habits and cultural norms do is establish the effective categories within which alternative actions will be compared and ranked, and there is nothing about category formation and category boundaries that the notion of rational choice can speak to. As a result, knowing that people are a rational choosers reveals very little about their choices. It will not reveal which options they view (or should view) as comparable and which they view (or should view) as incomparable. All it can reveal is how people will choose from within a category given that they have already established the categories, and this is not very much to reveal.

It is important to note that one of the triumphs of modernity that we celebrate as a culture is precisely the breakdown of categories like these. This is at least part of what self-determination means; people get to create their own categories. In this way, more of the self is open to self-determination than ever before. Exactly how choices such as these can be made rationally and whether people actually experience this freedom of choice as liberating are the questions. It was satisfying, 15 years ago, to be playing in a coed softball game - to be engaged in politics, socializing, and recreation at the same time-but this opportunity brought with it ambiguities that made the experience less than completely successful.

To choose so that preferences are maximized, people must know what is possible, and so the theory of rational choice assumes that people choose with complete information. A metaphor for choice with complete information is the situation that people confront when eating at a Chinese restaurant. There, arrayed on the menu, are countless dishes along with their costs. In the closed universe of the Chinese restaurant, complete information is available. People can deliberate about the various possibilities, and when they finally make a selection, it can truly be said to be preference maximizing.

However, perfect information is a myth, even in a Chinese restaurant. How many people really know what each of the dishes available is like? How often do people study the menu, awed and impressed at the variety available, only to order old favorites? Even in the closed and simple world of the Chinese restaurant, factors other than rational deliberation seem to govern choices. One of them, again, is habit. After agonizing over all the possibilities, people fall back, more often than not, on what they have done before. Another factor is tradition. People sit there trying to decide between novel shark's fin soup and familiar hot and sour soup, and finally they choose one of them, never considering the possibility that they could have both. One simply doesn't have two soups at a meal. If people fall back on habit and tradition even in a situation where rational deliberation with full information is possible, imagine how much more inclined they are to do so in the situations of everyday life that are full of open-ended uncertainty.

Modern rational-choice theory has acknowledged that the assumption of complete information is extremely unrealistic. Rather than assuming that people possess all the relevant information for making choices, choice theorists treat information as itself a "good," something that has a price (in time or money) and is thus a candidate for consumption along with more traditional goods (see, e.g., Payne, 1982; Payne, Bettman, \& Johnson, 1993). Treating information as a good makes the picture of rational choice more realistic, but a significant question remains: How much information is it rational to collect before actually making a consumption decision? Therefore, treating information as a good does not solve the problem of determining what is or is not a rational way to proceed.

The message here is that just as there is a series of constraints that makes real linguistic freedom possible in the domain of language, in the domain of choice, there is also a series of constraints on theoretical rational choice that makes actual rational choice possible. Cultural institutions go a long way toward telling people where they can choose and where they cannot, and within the domains where choice is allowed, these institutions determine what the possibilities are. These constraints on choice help solve the information problem. They solve the problem of having 
to compare things that are seemingly incomparable. In addition, and perhaps more significant, traditional constraints on choice may tell people in which domains of their lives the principles of rational choice are allowed to operate. They may protect patterns of behavior that are especially important to the functioning of the culture by removing them from the domain of choice altogether. Cultural traditions invest certain practices with a great deal of moral significance so that people will be discouraged from regarding them as matters of individual choice at all. Traditional morality serves as a kind of preventive medicine, protecting people from themselves (e.g., Shweder, 1990, 1991; Shweder \& LeVine, 1984).

These are a few of the ways in which the theory of rational choice presents an inaccurate or at least an incomplete picture of human preference and choice. The idea that people are rational choosers is on the one hand too rich, by giving people credit for more calculation and flexibility than they possess, and on the other hand too impoverished, by failing to appreciate a range of influences on decision making that are not themselves amenable to rational calculation. In recent years, investigators of preference and choice have come to see some of the limitations of the rational-choice framework and have tried to make it more realistic (see Baron, 1994, for a review). Central to these efforts is the work of Kahneman and Tversky (1979, 1984; Tversky \& Kahneman, 1981) that highlights the significance to choice of the manner in which alternatives are framed.

Consider being posed with this problem:

Imagine that you have decided to see a play where admission is $\$ 20$ a ticket. As you enter the theater you discover that you have lost a $\$ 20$ bill. Would you still pay $\$ 20$ for a ticket to the play? (Kahneman \& Tversky, 1984, p. 347)

Almost $90 \%$ of people asked this question said yes. In contrast,

Imagine that you have decided to see a play and paid the admission price of $\$ 20$ a ticket. As you enter the theater you discover that you have lost the ticket. The seat was not marked and the ticket can not be recovered. Would you pay $\$ 20$ for another ticket? (Kahneman \& Tversky, 1984, p. 347).

Now, less than $50 \%$ of people said yes. What is the difference between the two cases? From one perspective, they seem the same; both involve seeing a play and being $\$ 40$ poorer or not seeing it and being $\$ 20$ poorer. Yet people don't seem to see them as the same. What Kahneman and Tversky have suggested is that the difference between the two cases has to do with the way in which people frame their psychological accounts. Suppose that in a person's internal accounting system there is a cost-of-the-theater account. In the first case, the cost of the theater is $\$ 20$; the lost $\$ 20$ bill is not properly charged to that account. However, in the second case, the cost of the theater is $\$ 40$ (two tickets), and for many people, $\$ 40$ is too much to pay. On the other hand, suppose that the person's internal accounting system has a cost-of-a-day's-outing account. Now the two cases may well be equivalent in that the lost ticket and the lost $\$ 20$ both add the same amount to the cost of the day. So some people keep narrow cost-of-the-theater accounts, whereas others keep broader cost-of-the-day accounts. Which of them is rational? What is the way in which rational decision makers should keep their accounts?

The range of possible accounting systems people could use is enormous. For example, a journey to the theater could be just one entry in a much larger accountsay a getting-culture account, or a things-to-do-on-a-Friday-night account, or even a meeting-a-potential-spouse account-and how much this night at the theater is "worth" will depend on what account it is a part of. Forty dollars may be a lot to spend for getting culture, compared with available alternatives, but not much to spend to find a spouse. The flexibility of the accounting systems people can use raises an important question. If there are no norms or standards of rationality to judge accounting systems by, and if the number of possible accounting systems really is indefinitely large, what is it that determines which accounting systems people actually use?

In approaching this question, a look at the practices of professional accountants can be instructive. Professional accountants can also organize accounts in indefinitely many ways. What constrains the way they operate? There are three sources of constraints. One source is the legal system. There are tax and business regulations that impose a set of requirements on how the books must be kept. A second source is professional standards. The accounting profession establishes certain standards that guide how accounting is to be done. It maintains those standards in part by educating new accountants to do things in just that way. The final source is custom or habit. Accountants keep accounts in certain ways because they have always kept them in those ways or because the accountants who preceded them kept them in those ways. There is nothing especially privileged or rational about these constraints. Legal requirements could be different, as could professional standards, and habits are accidents of history. Yet, the constraints are there, and they serve to narrow and shape the way accountants do their work.

Precisely the same things could be said about the ways people keep their psychological accounts. They are influenced by legal and social sanctions, by customs and traditions, and by old habits. These influences may also be unprivileged and unjustified. Nevertheless, people inherit them and their effects on the keeping of accounts. People don't include their income taxes or the cost of supporting their children in their charitable-giving account, though they could. They don't treat school taxes as child-care expenses. They don't treat the money they give to houses of worship as entertainment costs. People may have good reasons for not doing these things, but they are not reasons that can be understood from within the perspective of the theory of rational choice. These reasons stem from the influence of culture on what categories people establish and what items they put in each category. Psychological accounting practices in different cultures are quite different from ours, but they are no more or less reasonable. 
An attempt to extend self-determination to everything would break down the habitual accounting practices people use. On the basis of the argument I have been sketching, this may make rational decision making impossible. The significant psychological consequence of this development could be that all the choices people make leave them with the dissatisfied feeling that they might have done better.

\section{Rational Choice and Cultural Constraint}

The plausibility of the theory of rational choice depends on the existence of markets and of money as a medium of exchange. This is what makes sensible the notion of human beings as perpetual choosers, with all options open and all possibilities comparable. To the extent that things can be priced (and the market is just the mechanism for the pricing of all things), they can be compared with one another, or so the theory of rational choice assumes.

However, not all social activity, or even all economic activity, is organized around markets and exchange. Imagine a small farmer living prior to the industrial revolution, say 300 years ago. For the most part, this farmer's activity would not have involved exchange in the market because there were few markets, and what markets there were rarely reached very far afield given the limits on available transport at the time. The farmer might have been engaged in raising crops, keeping chickens for eggs and cows for milk, doing occasional hunting and fishing, skinning animals for clothes, spinning wool, keeping the farm buildings and machinery in repair, caring for the plow horses, and so on. Not an item of exchange in the lot.

It might be tempting to argue that the preindustrial farmer was engaged in exchange. The farmer was exchanging labor time for goods instead of money, but it was a process of exchange nonetheless, no different in principle from the activity of the modern white collar worker. However, if we try to take this argument seriously and apply rational-choice concepts to the activity of the farmer, most of them don't make much sense. The amount of time that the farmer spent at various tasks cannot be treated as a measure of the value of their products to the farmer. Farming may take 10 times as much effort as hunting. From this, it does not follow that the farmer's crops were 10 times as valuable as meat. The farmer needed them both, and the time spent at these activities was dictated by the demands of the activities themselves and not by any calculation of value. The framework of rational choice is just the wrong framework for understanding what the farmer did. Certainly, there could have been better and worse farmers, rational and irrational ones, but rational farmers and rational choosers are not just two sides of the same coin.

What largely eliminated many of the constraints on economic activity that characterized the preindustrial farmer was the industrial revolution that began in the 17th century (see Hobsbawm, 1964; Polanyi, 1944; Schwartz, Schuldenfrei, \& Lacey, 1978). The industrial revolution took people away from the home and sent them into the factory (Marglin, 1976), making it difficult to engage in subsistence farming and production for exchange (wages) at the same time. Therefore, the notion that economic activity is exchange and the development of markets in which practically anything can be exchanged are very much products of the industrial revolution. This makes the rational chooser, as described by rational-choice theorists, a person who exists under only a rather restricted set of conditions that have been true only in the recent history of our species and then in only certain parts of the world.

Thus, the market system is not made possible by rational choosers; rather, it makes rational choosers possible. The implications of this line of argument for an account of human self-determination are significant. In the eyes of rational-choice theorists, principles of rational choice are not mere descriptions of particular points in history. They are laws of human nature, fundamental truths-both empirical and normative - about the human condition. One way of thinking about laws in general is as constraints on human activities. The law of gravitation is one such constraint; it keeps people from flying about uncontrollably. The law that prohibits going through red lights is another such constraint; it keeps people from driving their cars in whatever way they like. But these two kinds of laws are obviously very different. The constraint imposed by gravity is not human made, not self-imposed, and it cannot be repealed no matter how much people want to repeal it. The constraint on going through red lights, in contrast, is self-imposed and easily repealed.

Which of these kinds of constraints are described by the laws of rational choice? What I am suggesting is that the laws of rational choice are like traffic laws, not like gravity. We are almost certainly at the point in the history of our species (thus far) where rational choice with minimal constraints is most applicable to the human condition. However, this abundance of choice and explosion of markets-this liberation of the individual from traditional constraints - is experienced by only a minority of human beings. For most people in the world, individual choice is neither expected nor sought in many domains of activity (McCauley, et al., 1999; Shweder, Much, Mahapatra, \& Park, 1997). The critical point here is that one has to be mindful of culture-specific constraints and opportunities in considering the operation of any particular model of choice (see Fiske, 1991).

The constraints of culture affect not only what the preference hierarchy of individuals will be, but even how the individual-the self-is constituted. Markus and Kitayama (1991) have surveyed evidence indicating that the boundaries that separate the self from others are very much culture dependent. In cultures like that of the United States, the self is construed as an independent entity. The boundaries between the self and others are clear and distinct. Independence, autonomy, and self-determination are prized, and the values and preferences of each individual are given a status that is independent of the values and preferences of others. It is to explain the choices of a self like this that the theory of rational choice was constructed. However, in other cultures, even industrial cultures like Japan, the self is construed as an interdependent entity. Significant others form a part of the self, and their values 
and preferences are, in significant respects, one's own. In cultures like this, many of the conflicts Americans routinely face between doing the right thing and doing the self-interested thing evaporate. No doubt they are replaced by different conflicts, but these different conflicts are reflections of fundamentally different selves, with fundamentally different notions of preference and choice. Unless we understand how culture penetrates and defines the self, our investigation of the nature of human preferences and of self-determination can hardly be said to have begun. For many people in the world, the relevant unit for making decisions and experiencing their results is the family or the larger social group and not the individual. For people of these cultures, offering choices to individuals, rather than dictating them, may be experienced as burdensome rather than liberating (Iyengar \& Lepper, 1999a).

I believe that the dominance of rational-choice theory in the context of markets as a model for human autonomy has had a significant effect on Americans' aspirations with regard to self-determination. It is partly because we fit everything into a market framework that we expect to have choice and control in all domains of life (see Schwartz, 1997). The economist might say that this represents the triumph of industrial capitalism. Modern Americans refuse to have their behavior governed by tradition, and marketdriven affluence frees most of us from the dictates of necessity. As a result, everything is a matter of choice. This is the best of all possible worlds. Or is it?

\section{Tyranny of Freedom: The Evidence}

What I have done thus far is try to provide a plausibility argument that choice is constrained in the way that language is constrained, and that too much freedom from constraint is a bad thing. I want now to turn to some empirical evidence that I think supports this view. I begin with a discussion of depression.

The theory of learned helplessness has taught us about the importance of control and autonomy to mental health (e.g., Abramson, Metalsky, \& Alloy, 1989; Abramson, Seligman, \& Teasdale, 1978; Maier \& Seligman, 1976; Peterson, Maier, \& Seligman, 1993; Peterson \& Seligman, 1984; Seligman, 1975). In particular, helplessness has taught us that a lack of control, coupled with a certain characteristic style of causal explanation, creates candidates for clinical depression. Given that having control over significant things in one's life is important to preventing clinical depression, we can ask ourselves what we might expect the incidence of depression to be like in modern American society.

As I argued above, most of us now live in a world in which we experience control to a degree that people living in other times and places would think quite unimaginable. Extraordinary material wealth enables us to consume an astonishing quantity and variety of goods, and the magical mechanism of the market allows us an almost limitless array of choices. Further, this autonomy and control extend beyond the world of material goods. In careers, there is an enormous degree of mobility, both in career type and in geographical location. People are not constrained to do the work their parents did in the place where their parents did it, nor are people constrained to have only a single occupation for their entire working lives. Therefore, almost anything is possible. In personal life, religious, ethnic, racial, class, geographic, and even gender barriers to mate selection are rapidly disappearing. Moreover, one is free to choose whether to have kids or not, whether to have them early or late, whether to bear them or adopt them, whether to have them as part of a traditional marriage and family or as part of any of a host of nontraditional family arrangements. It is also increasingly easy to get out of marriages that have turned sour and, having done that, to arrange child custody in ways that suit the involved parties.

In summary, I think it is only a slight exaggeration to say that for the first time in human history, in the contemporary United States large numbers of people can live exactly the kind of lives they want, unconstrained by material, economic, or cultural limitations. This fact coupled with the helplessness theory of depression might lead one to expect clinical depression in the United States to be going the way of polio.

Instead, what we find is an explosive growth in the number of people with depression (e.g., Klerman et al., 1985; Robins et al., 1984). Some estimates are that depression is 10 times more likely to afflict someone now than at the turn of the century. Thus, we have a puzzle. The solution to this puzzle lies, I think, in several features of modern life that are the focus of this article.

First, I think that increases in experienced control over the years have been accompanied, stride-for-stride, by increases in expectations about control. The more we are allowed to be the masters of our fates in one domain of life after another, the more we expect to be. Education is expected to be stimulating and useful. Work is supposed to be exciting, socially valuable, and remunerative. Spouses are supposed to be sexually, emotionally, and intellectually stimulating and also loyal and comforting. Friends are supposed to be fun to be with and devoted. Children are supposed to be beautiful, smart, affectionate, obedient, and independent. Everything we buy is supposed to be the best of its kind. With all the choice available, people should never have to settle for things that are just good enough. In short, life is supposed to be perfect. Excessive emphasis on self-determination has, I believe, contributed to these unrealistic expectations.

Second, American culture has become more individualistic than it ever was before. What this means, I think, is that not only do people expect perfection in all things, but they expect to produce this perfection themselves. When they (inevitably) fail, I believe that the culture of individualism biases them toward making causal attributions that focus on internal rather than external causal factors. That is, I believe that the culture has established a kind of officially acceptable style of causal explanation, and it is one that focuses on the individual. As Seligman's research (e.g., Peterson \& Seligman, 1984) has led the way in demonstrating, this kind of causal attribution is just the kind to promote depression when people are faced with failure, and if my first point is correct, despite their increased control, 
people will inevitably be faced with many occasions that by their own lights count as failure.

Finally, the emphasis on individual autonomy and control may be undermining a crucial vaccine against depression: deep commitment and belonging to social groups and institutions - families, civic associations, faith communities, and the like. There is an inherent tension between being one's own person, or determining one's own self, and meaningful involvement in social groups. Doing the latter properly requires submerging one's self. Therefore, the more people focus on themselves-with respect both to goals and to the means of achieving those goals - the more their connections to others will be weakened. Robert Putnam (e.g., 1993, 1995, 1996) has recently attracted a great deal of attention to this deterioration of social connection in modern America, and in this context it is relevant to note a study by Egeland and Hostetter (1983) that showed an incidence of depression among the Amish of Lancaster County, Pennsylvania, that was about half the national rate, whereas other forms of psychopathology were much closer to national averages. The Amish, of course, are an extremely cohesive, tightly knit, traditional community.

Thus, the current literature on helplessness, control, and depression suggests that freedom of choice is not all it's cracked up to be, at least not with respect to psychological well-being. I think it is possible that a similar story can be told about body weight and diet. Despite the compelling evidence (summarized in Seligman, 1994) that people can do rather little about their body weight, the culture tells us that obesity is a matter of choice, personal control, and personal responsibility. It tells us that we should aspire to look perfect, and that if we don't, we have only ourselves to blame. How much of the modern epidemic of eating disorder stems from this particular mythology I do not know, but surely there would be less eating pathology if people understood the shapes of their bodies to be constraints rather than choices.

Consistent with the evidence that choice is not an unmixed blessing, results have begun to appear in the literature on human decision making to indicate that adding options for people can make the choice situation less rather than more attractive--that indeed, sometimes people prefer it if others make the choices for them (Beattie, Baron, Hershey, \& Spranca, 1994).

In one series of studies (Iyengar \& Lepper, 1999b) participants were more likely to purchase exotic jams or gourmet chocolates when they had 6 options from which to choose than when they had 30 options. In addition, those with fewer options expressed greater satisfaction with the choices they actually made. Further, college students were more likely to write an extra-credit essay and wrote better essays when they had 6 topics from which to choose than when they had 30 options. The authors suggested several possible factors that may underlie this effect. One is the avoidance of potential regret. The more options there are, the more likely it is one will make a nonoptimal choice, and this prospect undermines whatever pleasure one may get from one's actual choice. There is ample evidence that regret avoidance is a potent force in human decision mak- ing--perhaps even more potent than the loss avoidance that has been a significant feature of Kahneman and Tversky's (e.g., 1979) theory of decision making (Beattie et al., 1994; Bell, 1982, 1985; Loomis \& Sugden, 1982; Simenson, 1992; Zeelenberg, Beattie, van der Pligt, \& de Vries, 1996). This regret avoidance may be especially potent in people with low self-esteem (Josephs, Larrick, Steele, \& Nisbett, 1992). For such people, every choice opportunity presents the possibility that they will gather more evidence than they already have that they do not know how to make good decisions.

A second factor that may make increased choice options unattractive is that they create a seemingly intractable information problem. It is hard enough to gather the information and go through the deliberations needed to make the best choice among six options. To choose the best among 30 options is truly daunting. Therefore, rather than even try, people may disengage, choosing almost arbitrarily to get the process over with. As a result of this disengagement, many of the psychological processes that normally are recruited to enhance the attractiveness of the choices one makes may not be used (see Gilovich \& Medvec, 1995, for an account of some of these processes in the context of a theory of regret).

It should be noted that from the perspective of the norms of rational-choice theory, the demotivating effects of added options are truly paradoxical. If one already has a choice between Options A and B, how can adding Option $\mathrm{C}$ make one worse off? One can, after all, always ignore Option C and choose between A and B. Yet this demotivating effect is precisely what seems to occur, at least under some circumstances (see Redelmeier \& Shafir, 1995). And the commercial world seems already to know what experimental psychologists are just now discovering. Several major manufacturers of a variety of consumer products have been streamlining the number of options they provide customers, in response to a modest consumer rebellion against excessive choice. Proctor and Gamble, for example, reduced the number of versions of its very popular Head and Shoulders shampoo from a staggering 26 to "only" 15 , and they experienced a $10 \%$ increase in sales (Osnos, 1997).

\section{Conclusion}

This article has suggested two things. First, although we could live in a world in which everything was a matter of choice, we don't have to, and most people in the history of human society haven't. Second, were we to live in such a world, our mechanisms of rational choice would be overwhelmed rather than empowered. As I indicated at the outset, there is a degree of freedom that now exists in many of the most important domains of our lives that only a short time ago would have been unimaginable. Certainly, there are still strong vestiges of traditional constraint that remain in all of these domains, so that many freedoms that exist for everyone in theory can't be realized by everyone in practice, but there is no question of the direction in which things are moving. Every day it gets a little bit easier for 
individuals to do exactly what they want to do and to live exactly as they want to live.

Obviously, all of this freedom from traditional constraint is cause for celebration, particularly for those for whom traditional constraint was experienced as painful and oppressive. Largely because traditions are authoritarian and inflexible, modern Americans have fled from traditional institutions and values. Americans have chafed at being told what to do, at being told what was good for them. Traditions did not merely offer order and structure to people's lives; they insisted on it. To this inflexible insistence many Americans have said good riddance. It is much better to make up the rules of the games you play as you go along than to be forced to play those games by other people's rules-rules that don't seem to serve you and make no sense to you.

I have tried to suggest, however, that there is a dark side to all this freedom from constraint, to all this emphasis on individuals as the makers of their own worlds, their own destinies. It leaves people indecisive about what to do and why. Freedom of choice is a two-edged sword, for just on the other side of liberation sits chaos and paralysis. Thus, there is a price for freedom-danger. There is a price for enlightenment - uncertainty. There is a price for being able to change the rules of softball. You may not know what the new rules should be, and playing by new rules may damage what was good when you played by the old ones. Thus, in aspiring as a culture to offer individuals self-determination without constraint, we are not doing those individuals a favor.

What has all this to do with the future development of a positive psychology that will nurture strength rather than repair damage? Until now, psychology has been a significant contributor to the ethic of individual self-determination. The task before psychology now, I believe, is to pull back from this stance-but not indiscriminately. Rather, what psychology must do is figure out the "grammar" of human life choices - the set of constraints that actually enables freedom rather than impeding it.

When the great biologist Jacob von Uexkull said that "security is more important than wealth" (1938/1954, p. 26), more than half a century ago, what he was talking about was how evolution seemed to shape organisms so that their sensory systems were exquisitely attuned to just those environmental inputs that were critical to their survival. The forest is a much less interesting place to a squirrel than it is to a human being. Much that goes on in that forest goes right by the squirrel. Its sensory experience is thus impoverished relative to ours, but it notices what it needs to notice. Biology seems to supply the needed constraints on choice for most organisms. For people, those constraints have to come from culture. The task for a future psychology is to figure out what those constraints should be.

A final comment is necessary on the use of the word should in the previous sentence. Shoulds imply claims that are prescriptive rather than descriptive, and psychology, as a positive rather than a normative social science, has tried to steer away from shoulds. I believe that if psychologists are serious about turning psychology's power to developing a theory of optimal functioning, they can no longer avoid shoulds. I think that a richly developed positive psychology must do more than teach people how to do things-it must to do more than teach people effective techniques for getting what they want out of life. It must also tell them something about what they should be trying to get. That is, it must be informed by a vision of what a good hutnan life contains. Thus, a positive psychology will have to be willing to tell people that, say, a good, meaningful, productive human life includes commitment to education, commitment to family and to other social groups, commitment to excellence in one's activities, commitment to virtues such as honesty, loyalty, courage, and justice in one's dealings with others, and so on. Notice how the very notion that psychology might articulate a vision of the good life contradicts the emphasis on freedom, autonomy, and choice that are the subject of this article.

The official ideology of modern America poses an enormous barrier to this kind of contentful positive psychology. The ideology of America is the ideology of liberal individualism-let people decide for themselves what is good. Modern liberal culture is extremely reluctant to tell people what to do, and social science has internalized that credo: Don't be judgmental; help people get what they want, but don't tell them what they should be wanting.

It is one thing to encounter people in extreme psychological pain and to tell them,. gently, how to change the content of their lives to relieve that pain. Few people will object to psychologists who impose their values in this way to relieve suffering, but a positive psychology is a whole other story. A positive psychology will be indiscriminate in imposing its values; it will put its values in the community water supply, like fluoride. Is psychology prepared to be a science that promotes certain values instead of one that encourages self-actualization? If it is, will modern, liberal society stand for it?

To summarize this final point, once clinical psychologists had patients. Over the years, the discipline grew concerned that patient implied illness, which in turn implied a conception of health, a conception of the goal of therapy that the field did not really have. Thus, patients became clients. Doctors have patients. The patients come in sick, and the doctors make them well. Restoring and maintaining physical health and alleviating suffering are the goals of medicine. Lawyers, in contrast, have clients. Lawyers don't have goals for clients the way doctors have goals for patients. Rather, lawyers are there to help the clients achieve their own goals. Clients define their goals in a way that patients do not. Therefore, in moving from patients to clients, psychology moved from having the practitioner define the goal to having the recipient define the goal. What will psychologists call the recipients of their services if and when a positive psychology comes to fruition? I don't think that either patients or clients does justice to the grand vision that informs these beginnings of a positive psychology. The right term, I think, is students. Are psychologists prepared to argue that it is future generations of psychologists who should be society's teachers? I think that unless 
we are prepared to say yes to this question and to develop arguments about the content of a good human life, the potential achievements of a future positive psychology will always be limited. I also believe that the time to be thinking and talking about this very big and difficult issue is now, at the beginning, and not later, in the face of angry critics trying to put psychologists in their place.

\section{REFERENCES}

Abramson, L. Y., Metalsky, G. I., \& Alloy, L. B. (1989). Hopelessness depression: A theory-based subtype of depression. Psychological Review, 96, 358-372.

Abramson, L. Y., Seligman, M. E. P., \& Teasdale, J. D. (1978). Learned helplessness in humans: Critique and reformulation. Journal of Abnormal Psychology, 87, 49-74.

Baron, J. (1994). Thinking and deciding (2nd ed.). New York: Cambridge University Press.

Beattie, J., Baron, J., Hershey, J. C., \& Spranca, M. D. (1994). Psychological determinants of decision attitude. Journal of Behavioral Decision Making, 7, 129-144.

Bell, D. E. (1982). Regret in decision making under uncertainty. Operations Research. 30, 861-981.

Bell, D. E. (1985). Putting a premium on regret. Management Science, 31 , $117-120$.

Bowles, S. (1998). Endogenous preferences: The cultural consequences of markets and other economic institutions. Journal of Economic Literature, 36, 75-111.

Egeland, J. A., \& Hostetter, A. M. (1983). Amish study: I. Affective disorders among the Amish, 1976-1980. American Journal of Psychiatry, $140,56-61$.

Fiske, A. P. (1991). Structures of social life: The four elementary forms of human relations. New York: Free Press.

Gilovich, T., \& Medvec, V. H. (1995). The experience of regret: What, when, and why. Psychological Review, 102, 379-395.

Hobsbawm, E. J. (1964). Labouring men. London: Weidenfeld \& Nicholson.

Iyengar, S. S., \& Lepper, M. R. (1999a). Rethinking the value of choice: A cultural perspective on intrinsic motivation. Journal of Personality and Social Psychology, 76, 349-366.

Iyengar, S. S., \& Lepper, M. R. (1999b). When choice is demotivating. Manuscript in preparation.

Josephs, R. A., Larrick, R. P., Steele, C. M., \& Nisbett, R. E. (1992) Protecting the self from the negative consequences of risky decisions. Journal of Personality and Social Psychology, 62, 26-37.

Kahneman, D., \& Tversky, A. (1979). Prospect theory: An analysis of decisions under risk. Econometrika, 47, 263-291.

Kahneman, D., \& Tversky, A. (1984). Choices, values, and frames. American Psychologist, 39, 341-350.

Klerman, G. L., Lavori, P. W., Rice, J., Reich, T., Endicott, J., Andreasen, N. C., Keller, M. B., \& Hirschfeld, R. M. A. (1985). Birth cohort trends in rates of major depressive disorder among relatives of patients with affective disorder. Archives of General Psychiatry, 42, 689-693.

Loomis, G., \& Sugden, R. (1982). Regret theory: An alternative theory of rational choice under uncertainty. Economic Journal, 92, 805-824.

Maier, S. F., \& Seligman, M. E. P. (1976). Learned helplessness: Theory and evidence. Journal of Experimental Psychology: General, 105, $3-46$.

Marglin, S. (1976). What do bosses do? In A. Gorz (Ed.), The division of labour (pp. 13-54). London: Harvester Press.

Markus, H. R., \& Kitayama, S. (1991). Culture and the self: Implications for cognition, emotion, and motivation. Psychological Review, 98, $224-253$

McCauley, C., Rozin, P., \& Schwartz, B. (1999). On the origin and nature of preferences and values. Manuscript in preparation.
Osnos, E. (1997, September 27). Too many choices? Firms cut back on new products. Philadelphia Inquirer, pp. D1, D7.

Payne, J. W. (1982). Contingent decision behavior. Psychological Bulletin, 92, 382-402.

Payne. J. W., Bettman, J. R., \& Johnson, E. J. (1993). The adaptive decision maker. New York: Cambridge University Press.

Peterson, C., Maier, S. F., \& Seligman, M. E. P. (1993). Learned helplessness: A theory for the age of personal control. New York: Oxford University Press.

Peterson, C., \& Seligman, M. E. P. (1984). Causal explanations as a risk factor for depression: Theory and evidence. Psychological Review, 91 , $347-374$.

Polanyi, K. (1944). The great transformation. New York: Rinehart.

Putnam, R. D. (1993). The prosperous community. The American Prospect, 13, 34-40.

Putnam, R. D. (1995). Bowling alone: America'a declining social capital. Journal of Democracy, 6, 65-78.

Putnam, R. D. (1996). The strange disappearance of civic America. The American Prospect, 24, 34-48.

Redelmeier, D. A., \& Shafir, E. (1995). Medical decision making in situations that offer multiple alternatives. Joumal of the American Medical Association, 273, 302-305.

Robins, L. N., Helzer, J. E., Weissman, M. M., Orvaschel, H., Gruenberg, E., Burke, J. D., \& Regier, D. A. (1984). Lifetime prevalence of specific psychiatric disorders in three sites. Archives of General Psychiatry, 4l, $949-958$.

Schwartz, B. (1986). The battle for human nature: Science, morality, and modern life. New York: Norton.

Schwartz, B. (1994). The costs of living: How market freedom erodes the best things in life. New York: Norton.

Schwartz, B. (1997). Psychology, "idea technology," and ideology. Psychological Science, 8, 21-27

Schwartz, B., Schuldenfrei, R., \& Lacey, H. (1978). Operant psychology as factory psychology. Behaviorism, 6, 229-254.

Seligman, M. E. P. (1975). Helplessness: On depression, development, and death. San Francisco: Freeman.

Seligman, M. E. P. (1994). What you can change and what you can't. New York: Knopf.

Shweder, R. A. (1990). Cultural psychology: What is it? In J. W. Stigler, R. A. Shweder, \& G. Herdt (Eds.), Cultural psychology: Essays on comparative human development (pp. 1-46). Cambridge, England: Cambridge University Press.

Shweder, R. A. (1991). Thinking through cultures. Cambridge, MA: Harvard University Press.

Shweder, R. A., \& LeVine, R. A. (Eds.). (1984). Culture theory: Essays on mind, self, and emotion. Cambridge, England: Cambridge University Press.

Shweder, R. A., Much, N. C., Mahapatra, M., \& Park, L. (1997). The "big three" of morality (autonomy, community, divinity), and the "big three" explanations of suffering. In A. Brandt \& P. Rozin (Eds.), Morality and health (pp. 119-169). New York: Routledge.

Simenson, I. (1992). The influence of anticipating regret and responsibility on purchase decisions. Journal of Consumer Research, 19, 105-118.

Tversky, A., \& Kahneman, D. (1981). The framing of decisions and the psychology of choice. Science, 211, 453-458.

von Neumann, J., \& Morgenstern, O. (1944). Theory of games and economic behavior. Princeton, NJ: Princeton University Press.

von Uexkull, J. (1954). A stroll through the worlds of animals and men. In C. H. Schiller (Ed.), Instinctive behavior (pp. 3-59). New York: International Universities Press. (Original work published 1938)

Zeelenberg, M., Beattie. J., van der Pligt, J., \& de Vries, N. K. (1996). Consequences of regret aversion: Effects of expected feedback on risky decision making. Organizational Behavior and Human Decision Processes, $65,148-158$. 